\title{
IQ variations across time and race are explained by literacy differences
}

\author{
David F Marks
}

City University, London, Department of Psychology, Northampton Square, London EC1V $\mathrm{OHB}$.

Correspondence and requests for materials should be addressed to d.marks@city.ac.uk

\section{SUMMARY}

Intelligence quotient (IQ) scores are intended to assess the cognitive competences of individuals, groups and populations. A body of data collected during the last 50 years has revealed that IQ average population scores vary significantly over time, nationality, and race. The causes of these variations remain a mystery. Theories focusing on nutrition, brain size, dysgenic factors, social class and education have proved inexact or unsatisfactory. Here I describe a new explanation based on the fact that intelligence test performance requires a level of literacy not present in all people to the same degree. I show that literacy variations across time, place and race are highly associated with changes in IQ scores. These findings have widespread implications. Contemporary IQ test score differences between populations and racial groups are predicted to diminish with rises in universal literacy in the $21^{\text {st }}$ century. 
Intelligence quotient (IQ) test scores have been applied in a variety of ways to assess the cognitive competences of individuals, groups and populations. IQ test scores are used for selection purposes in education, industry and the military services. Since the early research of Spearman, it has been widely assumed that there is a general intelligence factor, $\mathrm{g}$, that underlies the performance of all individual cognitive tests and tasks. It has been suggested that $g$ is a fundamental property of the size ${ }^{2}$ or plasticity ${ }^{3}$ of the brain.

However, a huge body of data collected during the last 50 years has revealed that IQ scores show significant variations over time, place, and race. Three wellestablished phenomena of IQ tests remain unexplained. Firstly, during the period 1950-2000, in all countries studied to date, large increases in IQ test scores have occurred over time, the so-called "Flynn Effect". ${ }^{4,5,6}$ The IQ-score inflation rate has been approximately 3 points per decade. Yet there is no real evidence that people are becoming more intelligent and a satisfactory explanation of the Flynn effect has yet to be given.

Secondly, different races within a country have typically shown large IQ test score differences. In the USA the IQ scores of the black population has averaged about 1 standard deviation below the average for the white population. ${ }^{7}$ In the last few decades, the IQ-score gap between the US black and white populations has been narrowing. Recent analyses of standardization samples suggests that this gap has decreased 5-6 points from 1972 to 2002 . $^{8}$ Thirdly, countries show substantial and significant national differences in average IQ score. ${ }^{9,10}$ This, and 
the finding of black-white IQ score differences, has lent support to the hypothesis that intellectual and brain capacity vary across race $2,9,10,11$.

These three unexplained phenomena raise interesting fundamental questions about the nature of intelligence testing: What do intelligence tests really measure? What causes high and low IQ test scores? Is there an anomaly or artifact in intelligence test design? Is there is a hidden environmental or educational factor yet to be identified? Are brain capacity and intelligence genetically and racially linked?

To date, theories offered to explain the above three IQ phenomena have focused on environmental factors such as nutrition, ${ }^{12,13,14}$ social class $^{15}$ and education $^{16,17,18}$ or genetic theories such as brain size differences ${ }^{2,9,11,19}$ and dysgenic factors ${ }^{7}$. However, no consensus has been reached, and none of these theories is consistent with all of the available evidence. Here I present a new explanation for secular and population differences in IQ scores. The explanation is based on the fact that successful intelligence test performance requires a level of literacy not present in all people and populations to the same degree.

According to the most recent data, there are an estimated 774 million illiterate adults in the world, about $64 \%$ of whom are women. ${ }^{20}$ However, the literacy of populations has been increasing significantly over the last century. ${ }^{21}$ Researchers 
and policy makers have defined "functional literacy" as "using printed and written information to function in society, to achieve one's goals, and to develop one's knowledge and potential". 22 Literacy is assessed in a variety of different ways. The simplest, but least reliable, is self-reported literacy obtained simply by asking a person whether or not he/she can read and write. More objective measures of functional literacy use specially designed tests that measure different kinds of literacy skills such as prose, document and quantitative literacy. Surveys such as the National Adult Literacy Survey (NALS) ${ }^{23}$ employ a variety of everyday tasks such as finding a location on a map, understanding a newspaper article, or filling out an order form. Such tests require the application of written instructions to the solution of problems and, thus, overlap to some degree with items on intelligence tests.

The self-reported literacy of both the white and black populations of the USA has been increasing steadily since $1870 .^{25}$ Between 1992 and 2003 the gap in reading scores between black and white 17 -year olds decreased by 11 percent. ${ }^{23}$ Recent analyses suggest that the gap between black and white IQ scores has narrowed by 5-6 percent from 1972-2002.

At its most basic level a person is literate if he or she can read, write and understand a short simple statement on his or her everyday life. At more advanced levels, a literate person can write, read and comprehend prose, documents and quantitative expressions of high complexity. An IQ test requires 
a high level of literacy because it entails the understanding and application of complex information. An illiterate person is therefore ill equipped to complete an IQ test. Consequentially, if the proportion of illiterates in a population is relatively high, the average IQ test performance of the population will tend to be relatively low. On the other hand, if the proportion of illiterates in a population is relatively low, then the average IQ test performance of the population will tend be relatively high. If the average level of literacy in a population is increased, as a consequence of improvements in education, then the average IQ score of the population will also increase. However, these improvements in IQ performance will not be equally distributed through the entire population. IQ gains will be most evident in the lower half of the IQ score distribution because this is the population sector that previously would have obtained relatively low IQ scores as a consequence of their inability to comprehend intelligence test instructions.

This study is the first to systematically analyze the statistical association between literacy and IQ test scores across time, population, and race. Two kinds of evidence are presented here: (i) analyses of the relationship between mean IQ and literacy scores across populations and time; (ii) analyses of the distribution of population IQ test scores over time and place.

The analyses were carried out on data sets published in a variety of existing sources. In the majority of cases the original IQ data sets were derived from reports of national screening programmes carried out by military or educational services. Literacy data were obtained from a variety of published estimates. For the majority of analyses IQ and literacy were regressed against time and then 
against each other. In all cases linear or quadratic functions provided the best fit. Full details of the data sources are provided in the Figure legends.

\section{FI NDI NGS}

\section{(i) Correlations between IQ and literacy scores}

IQ and literacy data for the white population of the USA were available for the period 1932-1978. ${ }^{5,25} \mathrm{IQ}$ and literacy scores for US whites over this period had a correlation coefficient $R$ of $.95\left(R^{2}=.91 ; F(1,5)=48.12 ; p=.001\right)$ (Figure 1). IQ and literacy scores for the US black population were available for the period 1980-2000. ${ }^{8,25}$ IQ and literacy scores for the US black population over the period 1980-2000 had a correlation coefficient $R$ of $.90\left(R^{2}=.82 ; F(1,3)=13.87 ; p=\right.$ .0337) (Figure 2). Regression of the white-black IQ score gap ${ }^{8}$ on the whiteblack gap in 17 -year-old reading scores ${ }^{26}$ was fitted by a quadratic function and yielded an $R$-value of $.84\left(R^{2}=.71 ; F(2,5)=5.98 ; p=.047\right)$ (Figure 3 ).

FIGURES 1-3 ABOUT HERE

Danish literacy data for the 17-25 male population were available from 1960 to $1995{ }^{27}$ and IQ data for Danish 18-year old military draftees were available from 1960 until $2004 .^{28}$ Linear regressions for IQ and literacy against year showed a similar pattern. From 1960 until 1998 IQ scores among Danish military men 
showed linear increases until 1998 when IQ scores began to reduce in value continuously until 2004. Literacy scores in Danish men increased from 1960 until 1990 and from then onwards reversed downwards. Linear regression of average IQ against year over the 35-year period 1960-1995 produced a correlation coefficient $R$ of $.99\left(R^{2}=.98 ; F(1,17)=772.54 ; p<.0001\right)$. Linear regression of average literacy scores for Danish males over the same period produced a correlation coefficient of.78 $\left(\mathrm{R}^{2}=.60 ; \mathrm{F}(1,10)=15.09 ; \mathrm{p}=.003\right)$. The relationship between military men's average IQ and male average literacy was fitted well by a quadratic function with a correlation coefficient $R$ of .98 $\left(R^{2}=\right.$ $.95 ; \mathrm{F}(2,5)=49.09 ; \mathrm{p}=.0005)$ (Figure 4).

FIGURE 4 ABOUT HERE

IQ score data for Norwegian 18-20 year-old male conscripts were available for the period 1954 to $2002^{29}$ while literacy data for 17-25 year old Norwegian males was available from 1960 to $1995 .^{27}$ As for all the other analyses, linear regressions for IQ and literacy against year showed a similar pattern. As for the Danish data, changes in performance for Norwegian IQ and literacy occurred in two phases, the first between 1960 and 1975 being steep and linear, and the second between 1980 and 1995 reaching a plateau. Linear regression of IQ against year over the entire 35-year period gave a correlation coefficient ( $R$ ) of $.91\left(R^{2}=.82 ; F(1,6)=27.56 ; p=.0019\right)$ while the linear regression for literacy against year over the same period gave an R-value of .85 $\left(R^{2}=.72 ; F(1,6)=\right.$ 
15.45; $p=.0077)$. Linear regression of IQ against literacy over this period was almost perfect with an R-value of .98 $\left(R^{2}=.96 ; F(1,6)=164.89 ; p<.0001\right)$ (Figure 5).

The data from both Denmark and Norway showed a biphasic IQ-literacy relationship with a positive slope in phase one changing to a plateau or negative slope in phase two.

FIGURE 5 ABOUT HERE

The cross-sectional relationship between national average IQ scores $^{9}$ and average literacy scores for 86 countries $^{30}$ also shows a high correlation (Figure 6). Best fit to the data was obtained with a quadratic function giving an R-value of .83 $\left(\mathrm{R}^{2}=.69 ; \mathrm{F}(2,83)=94.22 ; \mathrm{p}<.0001\right)$. This highly significant correlation suggest that national differences in IQ scores are covariant with national differences in literacy ${ }^{31}$ and average IQ scores uncontrolled for literacy provide an unreliable measure of intellectual ability.

FIGURE 6 ABOUT HERE

\section{(ii) The IQ test score distribution}

If secular literacy improvements were causing the observed gains in IQ scores, 
then we would expect to observe two phenomena within the distribution of IQ test scores. Firstly, the standard deviation of the IQ test score distribution should become lower over a period when IQ test scores are increasing. Secondly, larger improvements in IQ scores should occur in the lower half rather than the upper half of the IQ test score distribution. Both effects would be the result of declining numbers of people with relatively low levels of literacy who are in the lower half of the IQ score distribution. As the literacy level of previously illiterate or lowliterate people improves, the standard deviation in the IQ-test score distribution is predicted to decline.

Data from a variety of sources have provided confirmation of both predictions. Improvements in IQ test performance have been especially large in verbal tests of IQ in the lower half of the IQ score distribution. In one recent Norwegian study the mean increase below the median score from the 1957-1959 to the 1993-2002 cohorts was about three times the increase above the median score. $^{29}$ In this study, the standard deviation of the IQ test score distribution decreased by $26 \%$ as the mean IQ (word similarities) score increased to its maximum over the period 1957-1996. In a similar Danish study, the standard deviation of the IQ test score distribution decreased by $22 \%$ as the mean test

score increased to its maximum over the period 1959-1998. ${ }^{28}$ In both studies it was observed that the mean IQ gains were associated with a much reduced proportion of low IQ scorers, and only a modest increase in high IQ scorers, as predicted by the literacy theory of intelligence test scores. 


\section{MPLI CATI ONS}

These findings have widespread implications for psychology, education, politics, and social policy. The results provide strong prima facie support for the hypothesis that IQ differences across time, nationality and race are caused by differences in literacy. The evidence shows that when the average literacy of a population increases, so does the population's average IQ. If literacy scores reach a plateau or begin to decline, IQ scores will also tend to plateau or begin to decline. Furthermore, as predicted, secular improvements in IQ are unequally distributed with the greatest gains occurring in the lower half of the IQ distribution.

A note of caution: correlation is not causation, and, before definite conclusions can be reached, evidence of the effect of literacy on IQ test performance is needed from experimental studies.

It has been claimed that differences in IQ scores between races and nationalities are caused by genetic differences between white Caucasian and black African, African-American, and African-Caribbean people. ${ }^{2,9,11}$ However the present findings show that the IQ data upon which the genetic and racial hypotheses are based is flawed. Literacy skills are learned and, with the appropriate educational environment, almost all members of a population (except those with learning disabilities) are able to acquire literacy skills. This evidence of a severe confounding between IQ scores and literacy reveals a 'missing link' between 
literacy and intelligence test performance that undoubtedly has led to misleading interpretations of intelligence test score data.

There is a consistently high correlation between population IQ and literacy scores in the range .79 to .98 . In essence, intelligence and literacy tests are measuring the same thing. High IQ is equivalent to high literacy and low IQ is equivalent to low literacy. Since the inception of intelligence testing, testers have been inadvertently measuring literacy. The so-called "intelligence quotient" (IQ) is a misnomer for a construct that could more accurately be termed the "literacy quotient" (LQ).

The literacy theory successfully explains three previously unexplained phenomena. Firstly, the so-called "Flynn effect", in which IQ test scores show secular gains, ${ }^{4,5}$ has been shown to be an inevitable consequence of secular literacy gains. The Flynn effect is simply an artefact of improving literacy: when the literacy of a population improves, so does its ability to successfully complete intelligence tests. However, as evidenced recently in Denmark and Norway, as literacy begins to wane, IQ scores also go into decline.

Secondly, the differences in IQ scores that exist today between different populations are artifacts of large, confounding literacy differences that exist between these populations. Thirdly, white-black differences in IQ scores are caused by literacy differences between these racial groups. Comparing the average IQ test scores of racial groups or populations without controlling for literacy is illegitimate. Genetic and racial theories ${ }^{2,7,9,10,11,19}$ of human intelligence 
are unfounded because, as shown here, the IQ test score evidence upon which such theories are based is fatally flawed. The white-black gap in US IQ test scores is narrowing and will continue to narrow as improved education enables all people an equal opportunity to gain literacy skills. National and racial differences that exist between IQ test scores today will diminish with increasing convergence in literacy that is predicted to occur universally in the $21^{\text {st }}$ century. 


\section{REFERENCES}

1

Spearman, C. S. The Abilities of Man (Macmillan, New York, 1927).

${ }^{2}$ Rushton, J.P. \& Rushton, E.W. Brain size, IQ, and racial group differences:

Evidence from musculoskeletal traits. Intelligence 31, 139-155 (2003).

${ }^{3}$ Shaw, P., Greenstein, D., Lerch, J. et al. Intellectual ability and cortical development in children and adolescents. Nature 440, 676-679 (2006).

${ }^{4}$ Flynn, J.R. The mean IQ of Americans: Massive gains 1932 to 1978 . Psychol Bull 95, 29-51 (1984).

5 Flynn, J.R. Massive IQ gains in 14 nations: What IQ tests really measure. Psychol Bull 101, 171-191 (1987).

6 Neisser, U. The Rising Curve. Long-term Gains in IQ and Related Measures (American Psychological Association, Washington, DC, 1998).

${ }^{7}$ Herrnstein, R.J . \& Murray, C. The Bell Curve: Intelligence and Class Structure in American Life (Free Press, New York, 1994).

8

Dickens, W.T. \& Flynn, J.R. Black Americans reduce the racial IQ gap: Evidence from standardisation samples. Psychol Sci 17, 913-920 (2006). 
9

Lynn, R. \& Vanhanen, T. IQ and the Wealth of Nations. (Praeger, Westport, CT, 2002).

10

Kanazawa, S. Mind the gap...in intelligence: Re-examining the relationship between inequality and health. Brit J of Health Psych 11, 623-642 (2006).

11

Jensen, A.R. The g Factor (Praeger, Westport, CT, 1998).

12

Sigman, M. \& Whaley, S.E. The role of nutrition in the development of intelligence, in The Rising Curve. Long-term Gains in IQ and Related Measures (ed. Neisser, U.) 155-182 (American Psychological Association, Washington, DC, 1998).

13

Martorell, R. Nutrition and the worldwide rise in IQ scores, in The Rising

Curve. Long-term Gains in IQ and Related Measures (ed. Neisser, U.) 183-206

(American Psychological Association, Washington, DC, 1998).

14

Lynn, R. In support of nutrition theory, in The Rising Curve. Long-term Gains in IQ and Related Measures (ed. Neisser, U.) 207-215 (American Psychological Association, Washington, DC, 1998).

15 Huang, M.H. \& Hauser, R.M. Trends in black-white test score differentials:II. The WORDSUM Vocabulary Test, in The Rising Curve. Long-term Gains in IQ and Related Measures (ed. Neisser, U.) 303-332 (American Psychological Association, Washington, DC, 1998). 
16

Greenfield, P.M. The cultural evolution of IQ, in The Rising Curve. Longterm Gains in IQ and Related Measures (ed. Neisser, U.) 81-123 (American Psychological Association, Washington, DC, 1998).

17

Williams, W.M. Are we raising smarter children today? School-and homerelated influences on IQ, in The Rising Curve. Long-term Gains in IQ and Related Measures (ed. Neisser, U.) 125-154 (American Psychological Association, Washington, DC, 1998).

18 Brody, N. Intelligence (Academic Press, San Diego, CA, 1992).

${ }^{19}$ Vernon, P.A., Wickett, J.A., Bazana, G. \& Stelmack, R.M. in Handbook of Intelligence (ed. Sternberg, R.J.) 245-264 (Cambridge University, Cambridge, 2000).

20 UNESCO Institute for Statistics Literacy topic URL: http: //www.uis.unesco.org/ev_en.php?ID=6401_201\&ID2=DO_TOPIC (2007). ${ }^{21}$ UNESCO I nstitute for Statistics URL: http: //stats. uis. unesco.org/ unesco/TableViewer/tableView.aspx?Reportl d=201 (2007).

22 Kirsch, I.S., J ungeblut, A., Jenkins, L. \& Kolstad, A. Adult Literacy in America: A First Look at the Results of the National Adult Literacy Survey (Educational Testing Service, Princeton, NJ, 1993). 
23

National Assessment of Adult Literacy (NAAL) A First Look at the Literacy of America's Adults in the $21^{\text {st }}$ Century URL:

http: //nces.ed.gov/NAAL/PDF/2006470.PDF (2004).

24

Gottfredson, L.S. Intelligence: Is it the epidemiologists' elusive "fundamental cause" of social class inequalities in health? J Personality \& Soc Psych 86, 174199 (2004).

25 Illiteracy http://nces.ed.gov/naal/lit_history.asp (2006).

26 Campbell, J.R., Hombo, C.M. \& Mazzeo, J. Trends in Academic Progress: Three Decades of Student Performance. NCES 200-469 (U.S. Department of Education, Office of Educational Research and Improvement, National Center for Educational Statistics, NAEP 1999, Washington, DC: 2000).

27 Coulombe, S. \& Tremblay, J-F. Literacy and growth. Topics in Macroeconomics 6, 0-32 (2006).

28 Teasdale, T.W. \& Owen, D.R. A long-term rise and recent decline in intelligence test performance: The Flynn Effect in reverse. Personality \& Ind Diff 39, 837-843 (2005).

29 Sundet, J.M., Barlaug, D.G. \& Torjussen, T.M. The end of the Flynn effect? A study of secular trends in mean intelligence test scores of Norwegian conscripts 
during half a century. Intelligence 32, 349-362 (2004).

${ }^{30}$ United Nations Human Development Report. Beyond Scarcity: Power, Poverty and Global Water Crisis (Palgrave Macmillan, Basingstoke, 2006).

31

Marks, D.F. Literacy not intelligence moderates the relationships between

economic development, income inequality, and health. Br. J. Health Psych 12,

179-184 (2007). 


\section{FI GURE LEGENDS}

FIGURE 1. Mean IQ scores against self-reported literacy for the white population of the USA. The literacy data were obtained from the National Center for Educational Statistics data on historical trends in illiteracy in the USA. ${ }^{25}$ This data set gives the percentage of persons 14 years old and over who were illiterate (unable to read or write in any language), by race and nativity: 1870 to 1979. The IQ test scores for white Americans for the period 1932 to 1978 were derived from Table 7 of Flynn (1987).

FIGURE 2. Mean IQ test scores against self-reported literacy for the black population of the USA. The literacy data were obtained from the National Center for Educational Statistics data on historical trends in illiteracy in the USA. ${ }^{25}$ IQ data from 1972 to 2002 were derived from Dickens and Flynn (2006). ${ }^{8}$ The IQ data for the required years were computed by taking unweighted averages of IQ scores presented in their Figure 2.

FIGURE 3. Differences in mean IQ scores against differences in reading scores between the white and black populations of the USA. The literacy data were derived the National Assessment of Educational Progress (NAEP) report (2004). ${ }^{26}$ The data set used in this analysis was derived from NAEP's long-term trend assessments in reading tests that were administered to white and black students 
aged 17 from 1971 to 2004. Differences in mean reading scores for white and black students were computed for the years 1972 to 2003 . The white-black IQ differences for the same years were computed from Figure 2 of Dickens and Flynn.

FIGURE 4. Mean IQ scores against literacy for the young male population of Denmark. The literacy scores were drawn from the data set compiled by Coulombe and Tremblay (2006). ${ }^{27}$ Data from the International Adult Literacy Study (IALS) were used to estimate the average literacy scores of men and women aged 17 to 25 for each synthetic cohort. This was done by determining the age of the cohort in 1994, when the IALS data were collected, and estimating the literacy indicators using data for the samples of adults at that age. The IQ data were obtained from the data set collated by Teasdale and Owen $(2005)^{28}$ based on the IQ scores of 500,000 Danish 18-year-old men collected by the Danish draft board between 1959 and 2004 .

FIGURE 5. Mean IQ scores against literacy for the young male population of Norway. Literacy data were drawn from the data set described in the legend for Figure 4. The IQ data were obtained from Table 1 of Sundet, Barlaug and Torjussen $(2004)^{29}$ based on ability tests administered from the mid-1950s until 2002 to 182,000 18-20-year-old male conscripts.

FIGURE 6. Mean IQ scores against literacy scores for 81 countries. The literacy data set was obtained from the United Nations Human Development Report 
(2006). ${ }^{30}$ These scores are provided by national governments and international bodies, the results of surveys and statistical analyses based on large samples. The IQ score data were extracted from Lynn and Vanhanen (2002). ${ }^{9}$ Only the 81 countries from this data set where actual IQ test scores had been measured are included. 
IQ

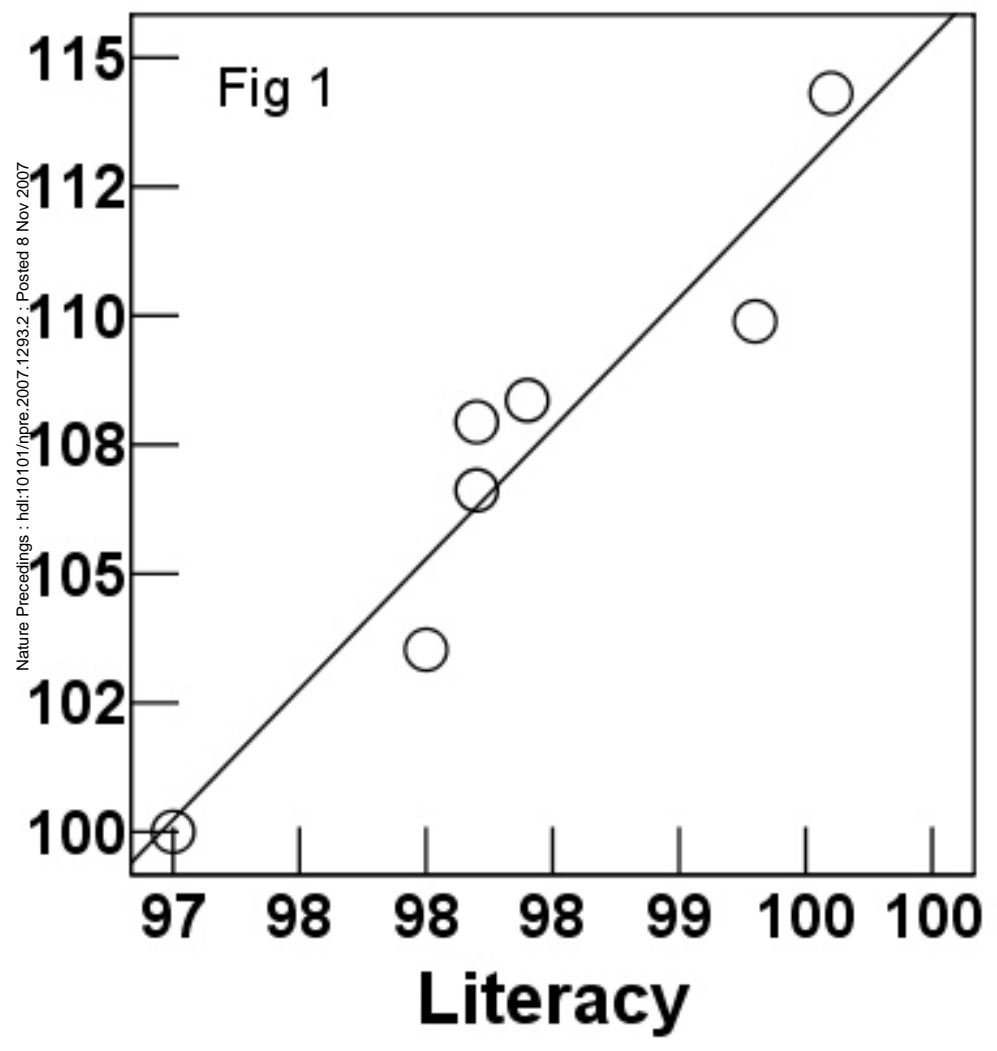


IQ

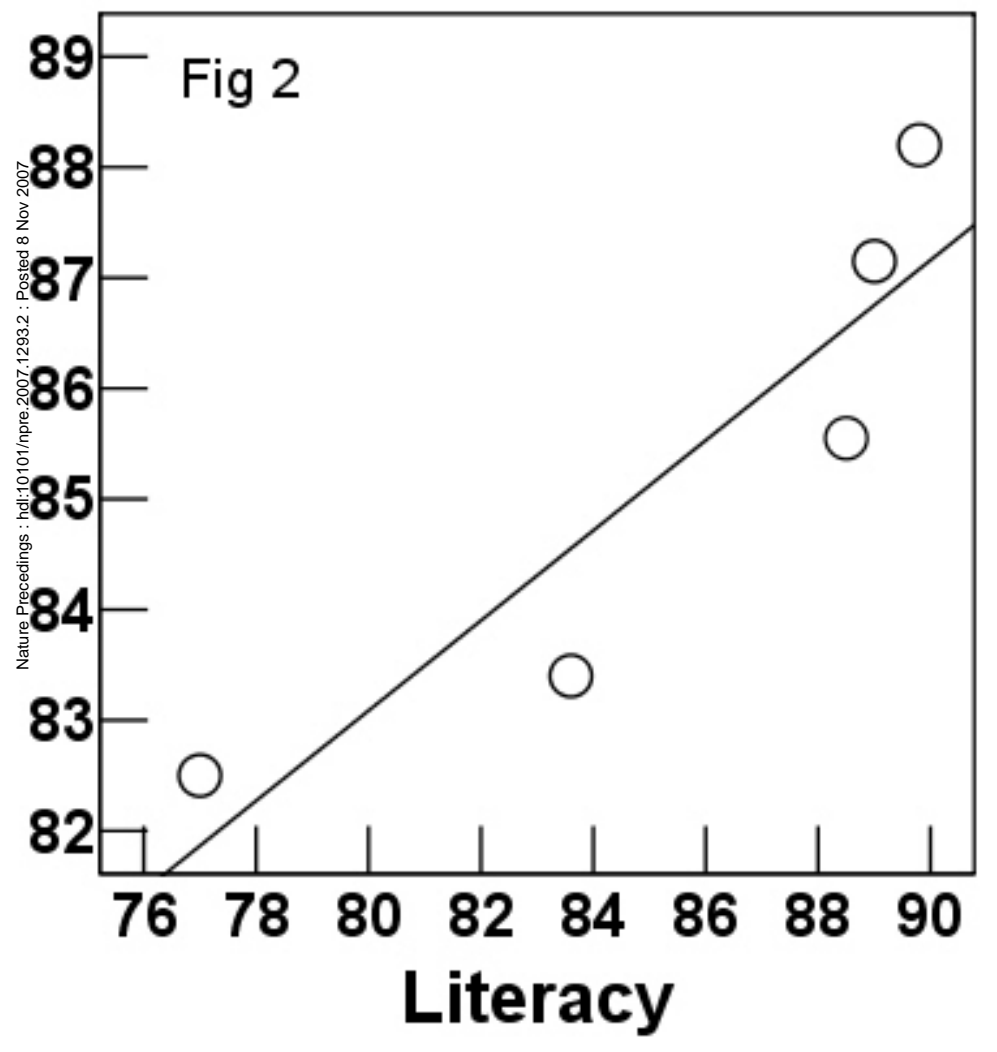




\section{W-B IQ}

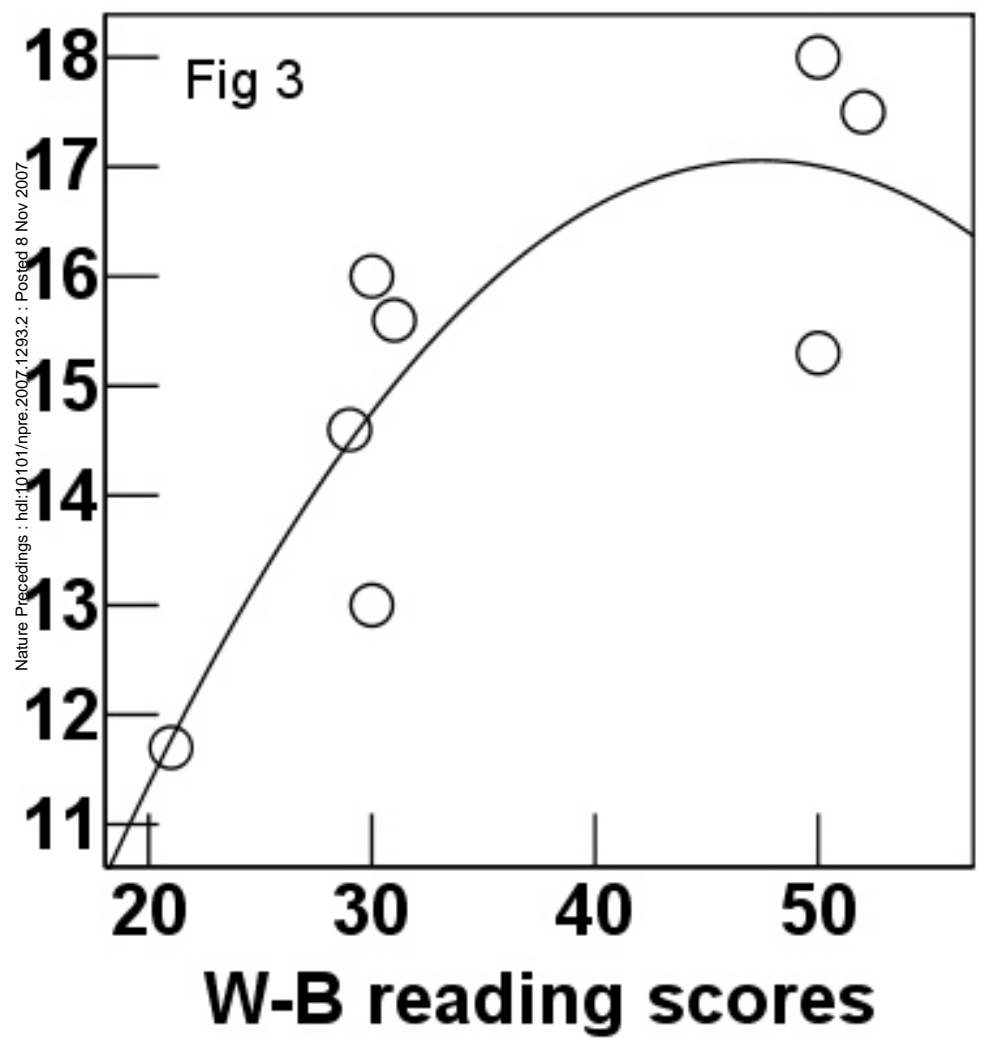




\section{Literacy}

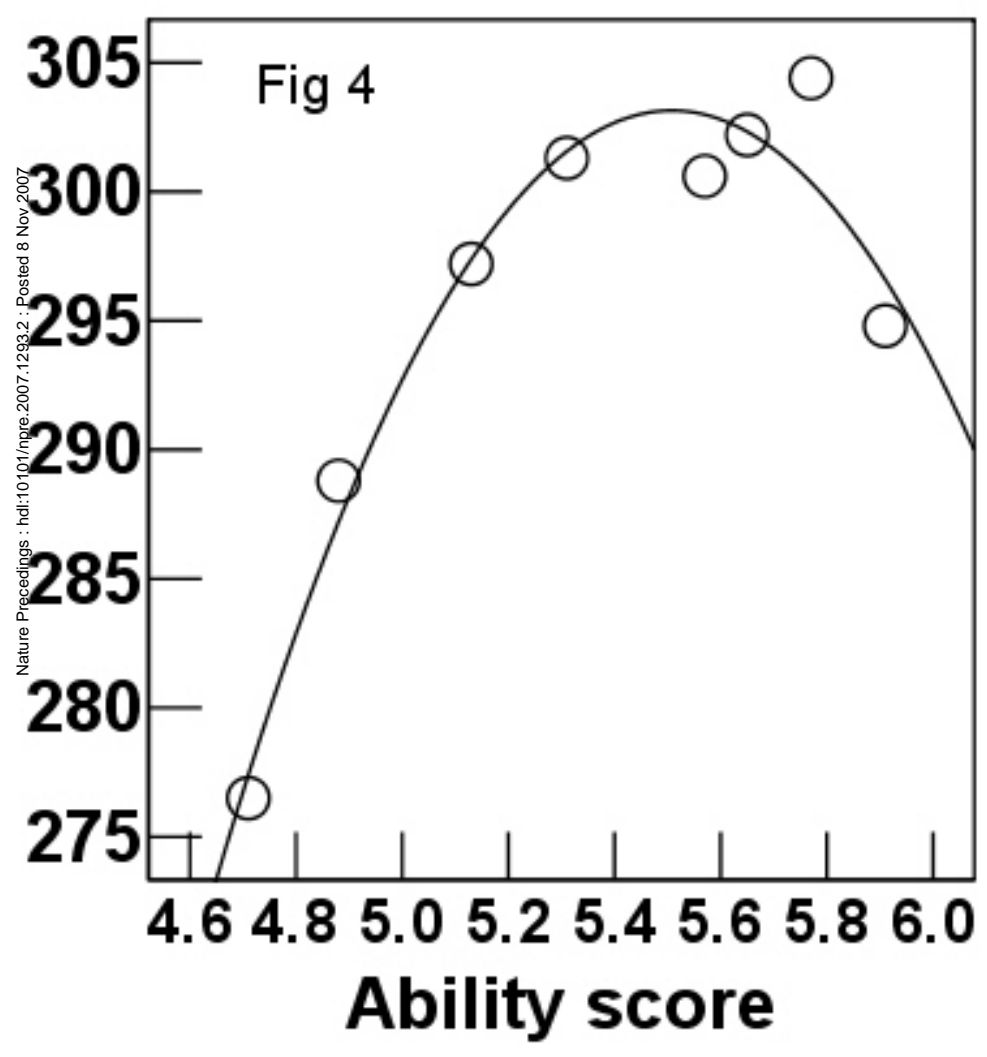


IQ

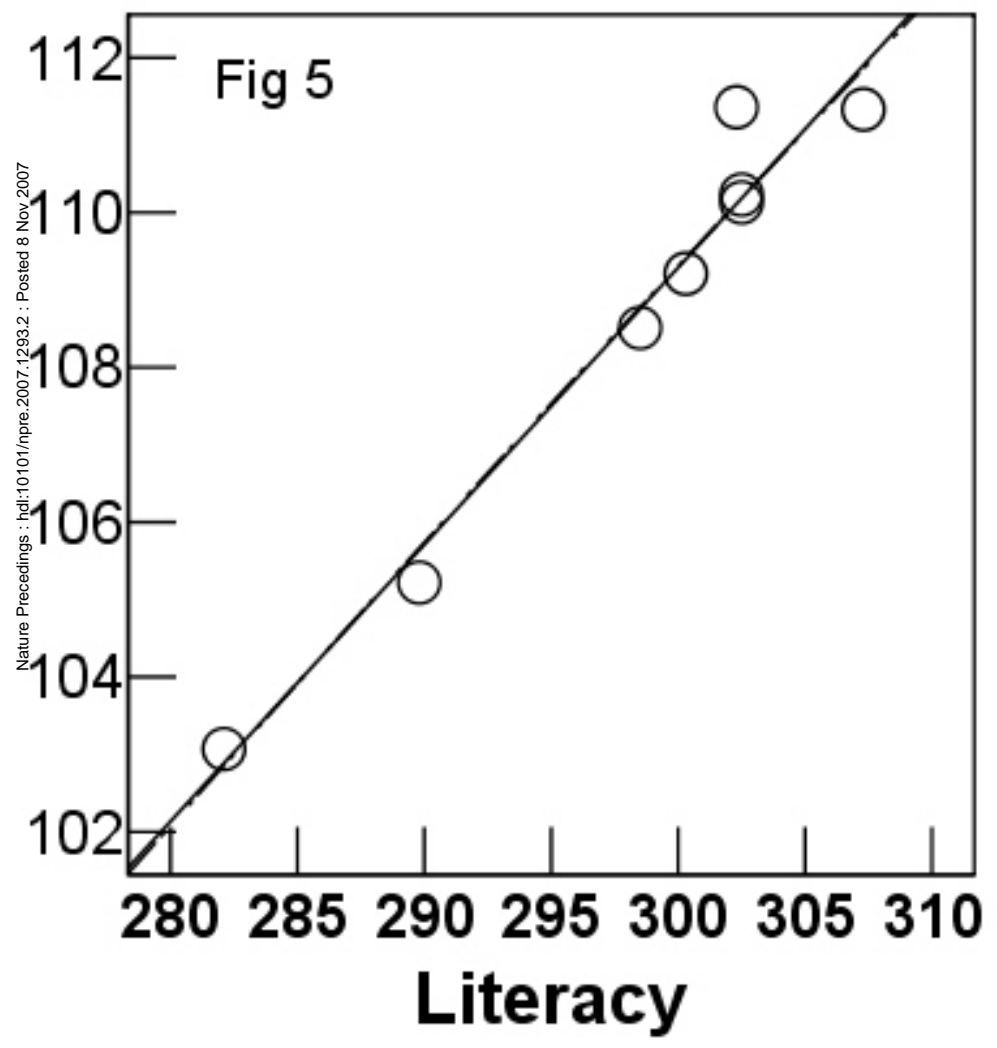




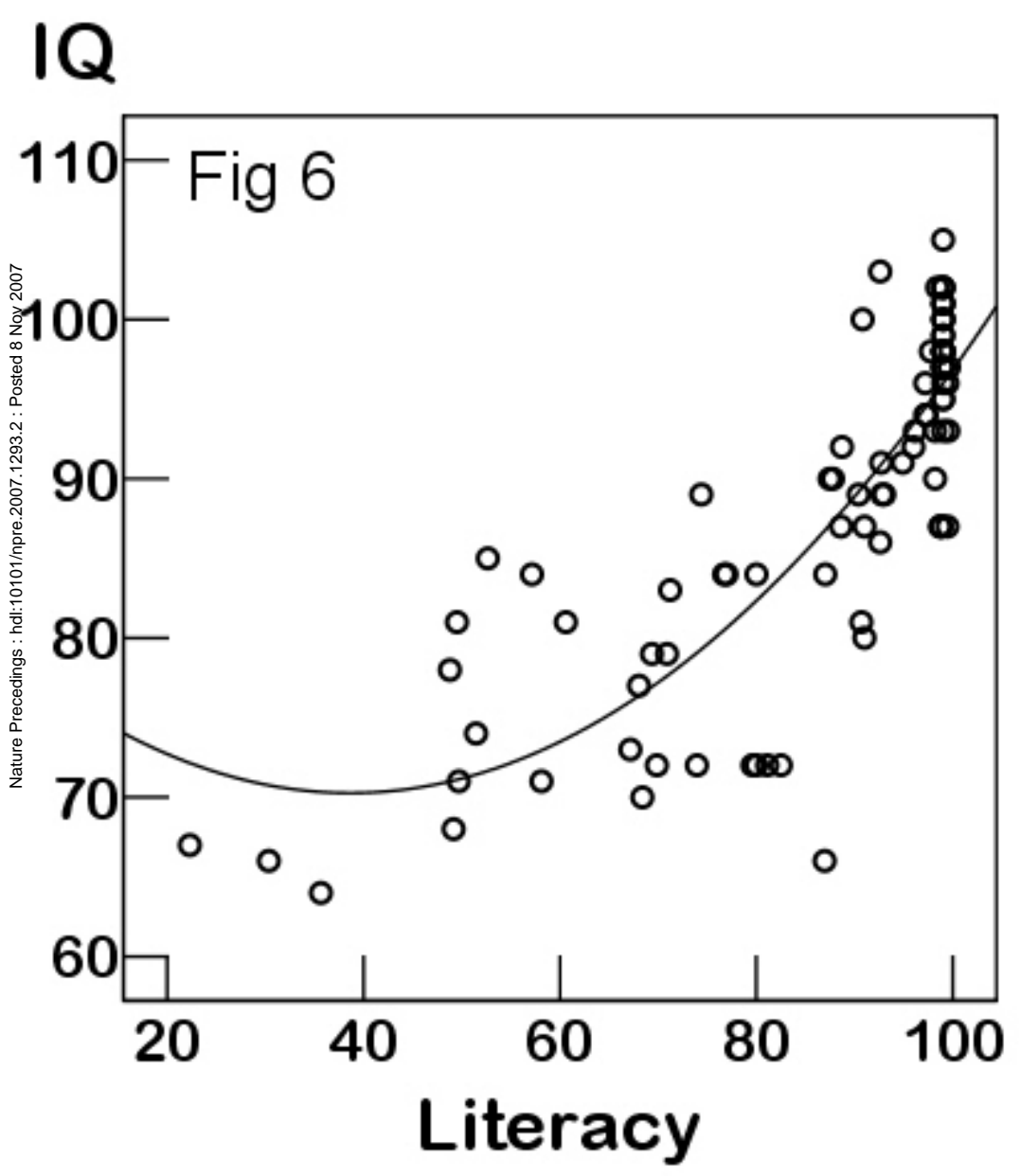




\section{SUPPLEMENTARY TABLE}

The main findings are summarized in Table 1.

Table 1 . Summary of data sets and main findings 

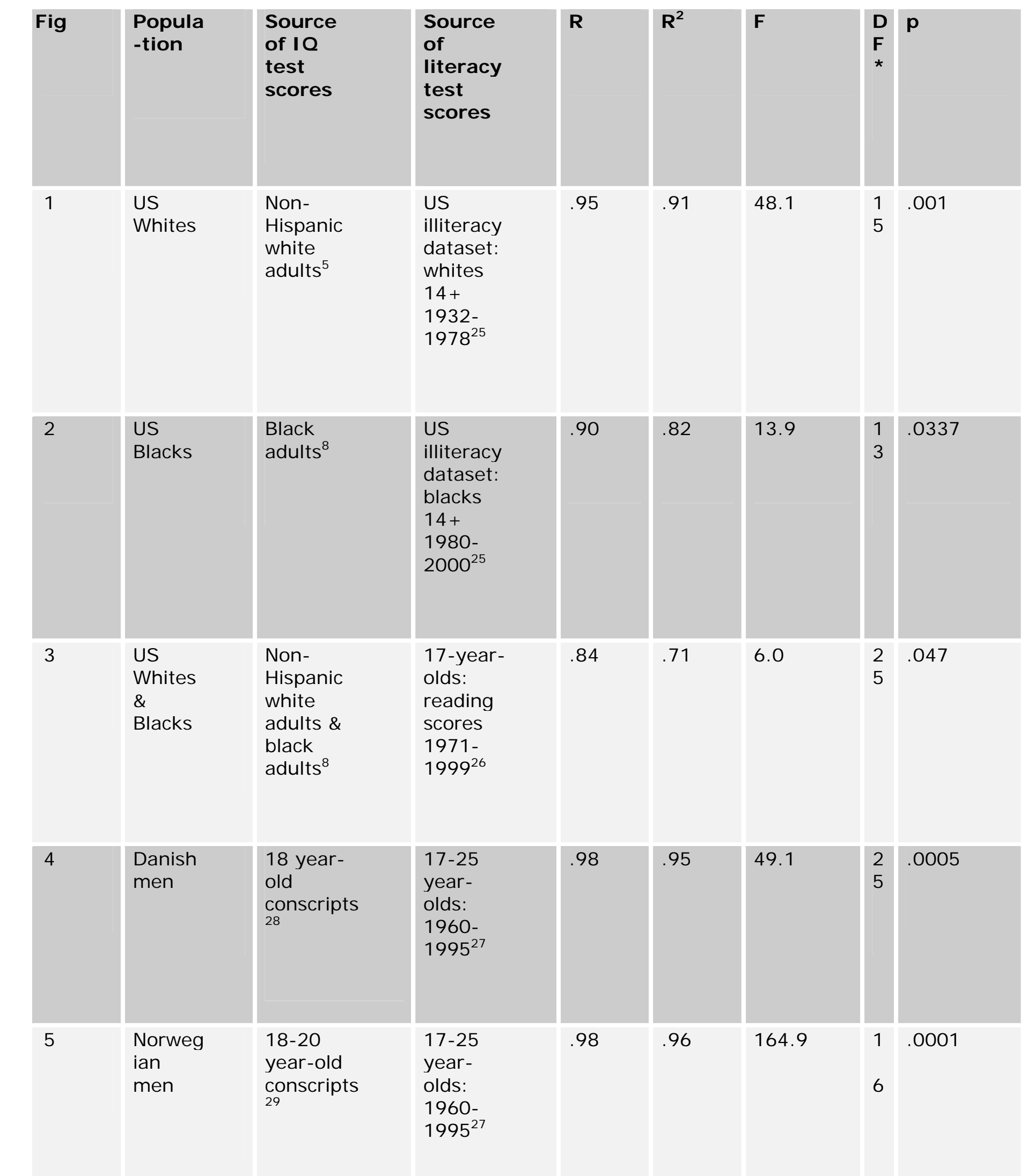

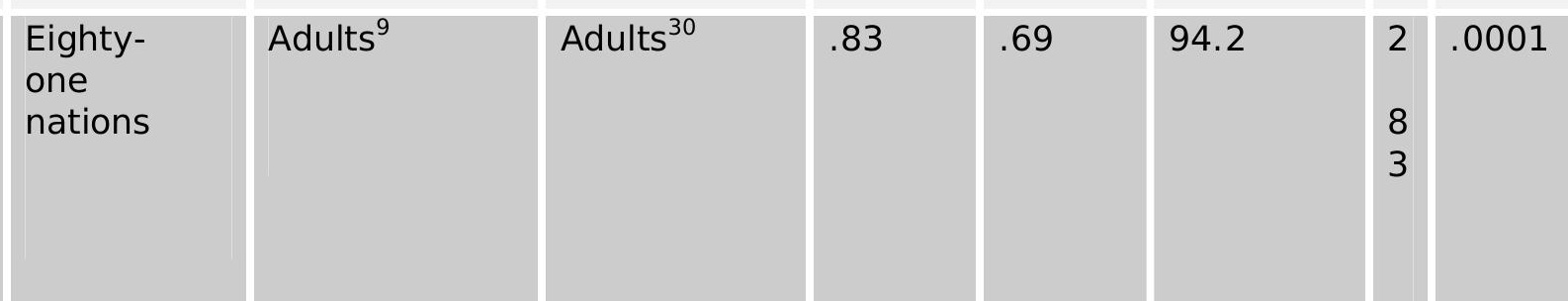


$* D F=$ degrees of freedom

\section{SUPPLEMENTARY NOTES}

Whenever possible descriptive statistics (means and standard deviations) derived from the original sources of raw data were employed. In a few cases literacy and IQ data were available over the same period of time but for different combinations of years. In such cases linear interpolation was used to provide a pairing of scores for the same set of years to enable regression to be carried out. For example, if the literacy scores for 1990 and 1995 for a specific population were known ( $x_{90}$ and $x 95$ respectively, $x_{95}>x_{90}$ ) and the IQ score for the same population was available only for 1993, and not for 1990 and 1995, then a literacy score $\left(\mathrm{x}_{93}\right)$ for 1993 would be estimated using the formula: $x_{93}=x_{90}+3\left(x_{95}-\right.$ $\left.x_{90}\right) / 5$.

All statistical analyses were carried out using SSPS 12.0.0 (release 4 Sep 2003).

The author acknowledges the assistance of Dr E.V.G. Estacio. 
